\title{
Using a safety management system to reduce errors and violations
}

\author{
Lesiba George Mollo MTech \\ Lecturer, Department of Built Environment, Central University of \\ Technology, Free State, South Africa (Orcid:0000-0001-5014-3294) \\ (corresponding author: Imollo@cut.ac.za)
}

Fidelis Emuze PhD

Professor and Head, Department of Built Environment, Central University of Technology, Free State, South Africa (Orcid:0000-0001-7714-4457)

\author{
John Smallwood PhD \\ Professor, Department of Construction Management, Nelson Mandela \\ University, Port Elizabeth, South Africa
}

This study discusses if and how a safety management system (SMS) mitigates or reduces errors and violations on construction sites. The study investigated SMS systems on three major projects in South Africa. The results affirmed that SMS helps to control hazards and risks, but the desired outcome could only be achieved if it is designed and implemented appropriately. The results suggested that on the construction sites visited, inadequate implementation ultimately resulted in errors and violations becoming the norm. The apparently poor implementation observed during the study was cause for concern. It should be addressed, jointly, by both workers and management.

\section{Introduction}

The construction industry has poor occupational health and safety (OHS) records. Working in the construction industry is considered to be high risk as it involves dangerous and challenging activities (Yiu et al., 2019). The construction industry around the world is infamous for its high number of fatalities (Shafique and Rafiq, 2019). For instance, Safe Work Australia Industry Statistics issued a report in 2014 stating that the Australian Construction Industry recorded 402 fatalities and 140, 448 serious injury claims for the period between 2003 and 2013 (Zou et al., 2017). In Great Britain, the Health and Safety Executive (HSE) reported that 147 workers were killed in the workplace in 2018/2019 (HSE, 2019a). In South Africa, the Department of Labour (DoL) reported that the construction industry recorded an average of 1.5-2.5 fatalities per week in 2016 (DoL, 2017).

The high accident and fatality rates in construction can be attributed to hazardous conditions and rapidly altering practices (Fan et al., 2014). Perlman et al. (2014) showed that the root causes of accidents in the industry are connected directly to errors and violations. Errors might include: a deviation from some path, either from an intended course of action or planned effort towards the desired goal, and inappropriate behaviour at work (Reason, 2016). Violations are a type of mistake, which happens when individuals fail to follow instructions or decide to make their own rules when undertaking an activity (HSE, 2019b). The difference between errors and violations is that violations are deliberate acts that often happen due to conscious decisions made by individuals in the workplace, whereas errors are not deliberate (HSE, 2019b).
To solve reported problems relating to errors and violations, contractors often adopt an SMS to achieve performance excellence (Wachter and Yorio, 2014). An SMS was introduced in the 1980s to mitigate workplace hazards, reduce injuries and minimise loss of material in the workplace (Yiu et al., 2019). The concept of an SMS requires the causes of accidents to be reported and analysed, and steps to be taken to prevent future events. The process of implementing an SMS should be well planned so that it enables site management teams and workers not only to identify and recognise risks and hazards easily, but also to communicate with each other during the construction process (Park and Kim, 2013).

The purpose of this study was to determine how an SMS would mitigate or reduce errors and violations effectively on project sites. The adoption of an SMS in construction would help safety management teams to learn how to control risks and hazards that might lead to errors and violations if not addressed. In this study, the concept of an SMS was applied in several building projects in Bloemfontein, South Africa. Therefore, this study provides an in-depth knowledge of an SMS, and understanding of implementing an SMS to reduce errors and violations in the construction industry.

The following sections of this paper provide an overview of SMS implementation in the construction industry. Thereafter, the research methods are explained, outlining the collection and analysis of data. The research findings are presented and discussed and, lastly, the research conclusion and recommendations for future studies are presented. 


\section{An overview of the safety management system}

An SMS is described as a system that is designed to enable the management of safety to prevent accidents in the industries (Yiu et al., 2018). An SMS is described as a formalised method to control safety management through the use of a framework that facilitates the identification, control and minimisation of safety risks (McKinnon, 2019). According to Yiu et al. (2019), an SMS was introduced to the construction industry in the 1980s by the European Union (EU) to reduce hazardous environments and mitigate the risk of injury on construction sites. The implementation of an SMS has become popular in the construction industry and the initial elements have been developed into an important factor which is regulated by most countries in the world (Álvarez-Santos et al., 2018). For instance, in the United Kingdom, the Accident Prevention Advisory Unit of HSE approved the OHS Acts to empower the introduction of SMSs in 1989 (Yiu et al., 2018). In Hong Kong, an SMS was legally imposed in 1991 to mitigate workplace accidents, injuries and promoting a safe working environment (Shafique and Rafiq, 2019).

Table 1 shows the elements of an SMS and their applications. An SMS has eight essential elements: hazard identification, safety inspection, OHS training on sites, safe work procedures, risk assessment plan, safety reporting system, toolbox talk and OHS policy. McKinnon (2019) pointed out that the elements of an SMS have a common outcome, which is to facilitate easy recognition and administration in the workplace.

Ismail et al. (2012) showed that the design and implementation of SMS in the construction industry in several countries is based on the standard practice for that country. For instance, in the United Kingdom, the HSE has launched a series of national and international standards, such as BS OHSAS 18001:2007 occupational health and safety (OHS) management systems and BS EN ISO 9001: 2008 quality management system, to encourage the adoption of SMS (Yiu et al., 2018). Hamid et al. (2008) showed that the integration of safety and management in the industry is based on OHSAS 18001:2007 and ISO 9001:2008, to reduce accidents and fatalities.

The objectives of developing and implementing an SMS are to eliminate workplace hazards and to reduce accidents (Accou and Reniers, 2019). However, the construction industry is still experiencing a high rate of accidents and fatalities (Fan et al., 2014) despite the adoption of SMSs to eliminate workplace hazards. Wachter and Yorio (2014) explained that the reason for this is that the industry cannot anticipate and control all possible work situations and tends to be slow to adapt to changing situations or uncertainties due to its rigid, controlled and complicated structure. The effects of inadequate implementation of an SMS are linked to errors and violations, which contribute to accidents in the construction industry. Work in construction is executed by people (artisans, general workers etc.) who are prone to errors while completing their tasks, which is related to effective implementation of an SMS (Wachter and Yorio, 2014).

\section{Research method}

To achieve the purpose of this research study, a mixed-method research design was used, as recommended by Plano Clark and Ivankova (2016). According to Plano Clark and Ivankova (2016), mixed-method research is described as a process which integrates quantitative and qualitative methods of data collection and analysis to achieve the purpose of research. For this

Table 1. Elements of SMS

\begin{tabular}{|c|c|c|c|}
\hline Number & SMS elements & Descriptions & Source \\
\hline 1 & Hazard identification & $\begin{array}{l}\text { A process to identify a situation or behaviour that has the potential to cause } \\
\text { injury or illness to people, damage to equipment or harm to the } \\
\text { environment. }\end{array}$ & McKinnon (2019) \\
\hline 2 & Safety inspection & $\begin{array}{l}\text { A process that is carried out to identify hazardous conditions and for the } \\
\text { modification of any such conditions at regular intervals or as appropriate. }\end{array}$ & Yiu et al. (2018) \\
\hline 3 & OHS training on sites & $\begin{array}{l}\text { A process of instructing or teaching personnel to work safely without causing } \\
\text { any hazards that might lead to accidents. }\end{array}$ & Yiu et al. (2018) \\
\hline 4 & Safe work procedures & $\begin{array}{l}\text { A systematic series of specific steps that guide personnel to work safely } \\
\text { through a task from start to finish. }\end{array}$ & Alli (2008) \\
\hline 5 & Risk assessment plan & $\begin{array}{l}\text { A systematic process of evaluating the potential risks associated with the } \\
\text { hazards that might cause harm to people in the workplace. }\end{array}$ & McKinnon (2019) \\
\hline 6 & Safety reporting system & $\begin{array}{l}\text { A systematic process of filling of reports and collection of information on safety } \\
\text { deficiencies in the workplace. }\end{array}$ & McKinnon (2019) \\
\hline 7 & Toolbox talk & $\begin{array}{l}\text { An informal group meeting or discussion that focuses on a particular safety } \\
\text { problem. }\end{array}$ & Alli (2008) \\
\hline 8 & OHS policy & $\begin{array}{l}\text { An organisational, documented statement of commitment to protecting the } \\
\text { health and safety of employees, as well as the surrounding community. }\end{array}$ & $\begin{array}{l}\text { Yiu et al. (2018); } \\
\text { McKinnon (2019) }\end{array}$ \\
\hline
\end{tabular}


study, qualitative data were collected from case studies, as recommended by Hancock and Algozzine (2011). A multiple case study research approach, as illustrated by Hancock and Algozzine (2011), was used for this study in Bloemfontein, South Africa. Three construction site projects in Bloemfontein were selected because all three projects were building projects and the nature of the building works exposed construction professionals and workers to different hazards that might cause errors and violations. Thus, purposive sampling was used to select multiple case-study projects (Hancock and Algozzine, 2011). For each case-study project, the researcher obtained permission from the construction manager to collect the study data on their project site and to interview participants who were members of the construction teams, including construction managers, site engineers, foremen/supervisors, artisans and general workers (Table 2).

The qualitative data for the study were collected from multiple case-study projects using open-ended questions, semistructured interviews and focus group interviews as suggested by Flick (2014). The researcher interviewed only the members of the construction teams who worked on the selected project sites as shown in Table 2. In all the interviews, the background of the study was explained to each participant and they were allowed to respond to the questions while expressing their opinion and knowledge of work relating to the research topic.
Data were collected also from focus group interviews with groups made up of the artisans and general workers. The use of focus group interviews on each site enabled each participant (artisan or general worker) to discuss issues relating to SMS as a group, rather than simply as individuals, as explained by Bryman (2012). At the start of each focus group interview, the background of the study was explained to the participants. During the focus group interviews, participants were asked to have open discussions and to give each participant a chance to express their opinion without interference. In case-study project 1 , the focus group interviews involved a group of artisans (four bricklayers) and a group of general workers who were divided into two groups: one group of five general workers and one of four general workers. In case-study project 3 , the focus group interview involved a group of artisans (seven bricklayers). All the interviews took place at the construction sites during the lunch period.

All the semi-structured and focus group interviews were carried out face-to-face by the researcher on the case-project sites in Bloemfontein, between July 2018 and April 2019, and lasted between 30 and $60 \mathrm{~min}$. The interviews were recorded and later transcribed. Thereafter, the qualitative data were analysed using thematic analysis, as illustrated by Bryman (2012), where themes were identified by which to interpret and summarise the qualitative data collected. During the analysis

Table 2. Research sample

\begin{tabular}{|c|c|c|c|}
\hline Multiple case-study projects & $\begin{array}{l}\text { Members of the construction teams } \\
\text { (interviewees) }\end{array}$ & $\begin{array}{l}\text { Number of } \\
\text { responses }\end{array}$ & $\begin{array}{c}\text { Response } \\
\text { rate: \% }\end{array}$ \\
\hline \multicolumn{4}{|l|}{ Case-study project 1: } \\
\hline \multirow[t]{7}{*}{ The new TFS distribution warehouse structure project } & $1 \times$ construction manager & 18.00 & 46.00 \\
\hline & $1 \times$ safety manager & & \\
\hline & $1 \times$ site engineer & & \\
\hline & $1 \times$ senior foreman & & \\
\hline & $1 \times$ junior foreman & & \\
\hline & $4 \times$ a group of artisans & & \\
\hline & $9 \times$ a group of general workers & & \\
\hline \multicolumn{4}{|l|}{ Case-study project 2: } \\
\hline \multirow{8}{*}{$\begin{array}{l}\text { The new University of Free State (UFS) South Campus } \\
\text { Student Housing Unit } 05\end{array}$} & $1 \times$ safety manager & 9.00 & 23.00 \\
\hline & $1 \times$ construction manager & & \\
\hline & $1 \times$ senior site engineer & & \\
\hline & $1 \times$ senior site quantity surveyor & & \\
\hline & $1 \times$ senior foreman & & \\
\hline & $1 \times$ junior site engineer & & \\
\hline & $1 \times$ junior foreman & & \\
\hline & $2 \times$ student supervisor & & \\
\hline \multicolumn{4}{|l|}{ Case-study project 3: } \\
\hline \multirow{6}{*}{$\begin{array}{l}\text { The new University of Free State (UFS) South Campus } \\
\text { Student Housing Unit } 06\end{array}$} & $1 \times$ construction manager & 12.00 & 31.00 \\
\hline & $1 \times$ safety manager & & \\
\hline & $1 \times$ site engineer & & \\
\hline & $1 \times$ senior foreman & & \\
\hline & $1 \times$ junior foreman & & \\
\hline & $7 \times$ a group of artisans & & \\
\hline Total interviewees & & 39.00 & 100.00 \\
\hline
\end{tabular}


of the qualitative data, responses which failed to address the issues relating to SMS on construction sites were deleted.

Thereafter, quantitative data were collected using a survey questionnaire (Plano Clark and Ivankova, 2016). The purpose of the survey was to enhance the insights from the qualitative data. The design of the questionnaire was based on an in-depth analysis of the relevant literature review as summarised in Table 1. Eight SMS elements were identified that contribute to errors and violations which can cause harm if not prevented.

The survey questionnaire was designed using QuestionPro Software on an online survey platform. The survey link to the questionnaire was sent to the South African Council for Project and Construction Management Professionals (SACPCMP) to distribute the survey link to its members on its database. Members who were registered either as professional or candidate's construction managers, construction health and safety managers, construction health and safety officers and construction health and safety agents were targeted to participate in the survey. Thus, purposive sampling was used to select the participants, as explained by Plano Clark and Ivankova (2016). The demographic profile of the participants is shown in Table 3 .

The survey of professionals was conducted between 15 July 2019 and 15 October 2019. Thus, the survey adopted crosssectional studies as explained by Plano Clark and Ivankova (2016). In total, 162 responses were submitted on the survey platform as shown in Table 4. Of these, only 158 were valid and three responses were excluded, as indicated in the case processing summary in Table 4.

Table 3. Demographic profile of the participants

\begin{tabular}{|llc|}
\hline Participants of organisations & Number $(\boldsymbol{N})$ & Percentage \\
\hline Construction firms/contractors & 78 & 48.00 \\
Clients (public/private sectors) & 27 & 17.00 \\
Civil engineering consultants & 8 & 5.00 \\
Health and safety consultants & 40 & 25.00 \\
Architect consultants & 5 & 3.00 \\
Quantity surveying consultants & 4 & 2.00 \\
Total participants & $\mathbf{1 6 2}$ & $\mathbf{1 0 0 . 0}$
\end{tabular}

Table 4. Case processing summary

\begin{tabular}{|llcr|}
\hline & & Number $(\boldsymbol{N})$ & Percentage \\
\hline \multirow{3}{*}{ Cases } & Valid & 158 & 97.5 \\
& Excluded & & \\
& Total & 4 & 2.5 \\
& Total & 162 & 100.0 \\
\hline
\end{tabular}

aListwise deletion based on all variables in the procedure
The survey questionnaire was designed using a Likert scale of $0-5$, as recommended by Plano Clark and Ivankova (2016), where $0=$ unsure, $1=$ minor, $2=$ above minor, $3=$ neutral, $4=$ near major and $5=$ major. The quantitative data collected were analysed using the Statistical Package for Social Science (SPSS). The analysis of the quantitative data, showing mean scores (MS) and standard deviations (SD) is presented in Table 5. The reliability of the analysed data was tested statistically, using Cronbach's alpha (Plano Clark and Ivankova, 2016).

\section{Research results}

The summary of the research results in this section is presented in two sub-sections. Section 4.1 contains the qualitative data while Section 4.2 contains the quantitative data.

\subsection{SMS and its effects on errors and violations on project sites}

In response to the importance of having an appropriate SMS on construction sites, several participants stated that their employers had hired a safety manager who was responsible for designing an SMS to be deployed on their project sites to identify and eliminate risks and hazards that have the potential to cause accidents. A safety manager interviewed in case-study project 1 explained that his employer had created a safety management division, which was responsible for designing an effective SMS at the start of the project. The participant elaborated further that some of the SMS elements which they had adopted to eliminate hazards included a risk assessment tool, safe work procedures, safety training and safety observation inspections. He explained further that his safety measures had helped his organisation to record not a single accident on their construction sites. The participant is quoted as follows:

One of the reasons why we have not recorded a single accident is because safety practice is the responsibility of everyone working on sites. We don't just rely on our adopted safety system, but we rely mostly on our worker's co-operation towards safety practice.

Table 5. SMS elements to prevent errors and violations on project sites

\begin{tabular}{|lccc|}
\hline Elements of SMS & Mean & Standard deviation & Rate \\
\hline Hazard identification & 3.80 & 1.434 & 1 \\
Safety inspection & 3.61 & 1.453 & 2 \\
OHS training on sites & 3.54 & 1.483 & 3 \\
Safe work procedures & 3.44 & 1.448 & 4 \\
Risk assessment plan & 3.42 & 1.486 & 5 \\
Safety reporting system & 3.41 & 1.493 & 6 \\
Toolbox talk & 3.01 & 1.548 & 7 \\
OHS policy & 2.81 & 1.498 & 8 \\
\hline
\end{tabular}


This statement by a safety manager in case-study project 1 , relating to the use of a risk assessment plan was corroborated by a construction manager in case-study project 2 . For instance, the participant explained that their employers had appointed a safety management team to design an effective SMS to promote a safe working environment by identifying and eliminating hazards that might cause accidents if not prevented.

However, it was found that the general workers interviewed had different responses compared with the previous responses by the safety managers and construction manager. The group of general workers in case-study project 1 are quoted as follows:

The adoption of an SMS is very critical on our project site as the system protect us from some of our supervisors who often put our lives in danger. This is because often our supervisors tend to abuse their powers by instructing us to work in unsafe working conditions due to their desire to reach high-level productivity.

It was reported further by a group of artisans in case-study project 3 that an SMS helps them to understand the OHS policy and how to work safely, how to use tools and equipment safely, and the importance of wearing personal protective equipment (PPE) all the time.

Our safety manager makes use of the SMS to teaches us to understand the importance of using the appropriate equipment for the designed tasks and to protect our body from getting hurt by always wearing PPE at all the times.

In contrast to the above statement by a group of artisans in case-study project 3 , it was found that learning how to work safely and using tools and equipment safely in case-study project 2 was practically impossible. It was reported by several participants that they had witnessed an accident which was caused by a concrete mixing machine. One of the workers was working with a concrete operator. He was standing next to a concrete drum and while pouring the concrete, he lost his footing and his hand was caught inside the concrete drum which ripped off his finger.

In response to procedures which must be followed when designing an effective SMS, most of the participants from the case-study projects explained that an SMS must be designed according to the Construction Regulations of 2014, which were issued by the DoL in South Africa. Thus, it is known that, with regard to OHS, the construction industry in South Africa is regulated by the DoL. The Construction Regulations of 2014 help role-players in the construction industry to design an effective SMS according to the Occupational Health and
Safety Act 85 (1993). Some of the participants' responses are quoted as follows:

We are responsible to protect everyone working on our construction sites and we have adopted the Construction Regulations of 2014 to help our safety team to design an effective SMS which is responsible to reduce risks and eliminate hazards which have the potential to cause accidents. (Safety manager and construction manager in case-study project 3.)

It is important for our safety manager to study and understand the safety guidelines or standards which are provided by our clients at the start of the project. Thereafter, our safety management team would adopt the Construction Regulations of 2014 and use it to design our SMS. (Safety manager in case-study project 1.)

The construction manager interviewed in case-study project 1 and senior site engineer in case-study project 2 stated that, after the safety management team had designed the SMS, the system would be sent to the clients for evaluation and, if the clients did not approve the system, they would not permit them to start with the construction work. It was reported further by a senior and junior foreman in case-study project 3 that their SMS stipulated that all safety warning signage must be designed and printed according to the safety standard issued in the Construction Regulations of 2014. The safety warning signage must be designed using the latest safety standard when printing new labels, and the writing must be legible and written in a common language which would be understood by everyone on site. The participants further explained that, on their project site, all of their safety warning signs were written in English, but their safety manager translated all the safety warning messages for the workers, using Sesotho (a South African local language) so that all the workers who could not read English would understand fully the safety message conveyed by the safety warning signage. Figure 1 shows an example of a safety warning sign installed at the main entrance of the project site.

In response to the impacts of errors and violations on construction sites, it was reported by several participants from the case-study projects that the use of a risk assessment plan helped them to identify hazards and the process of analysing hazards helped them to eliminate errors and violations. For instance, it was reported by a safety manager in case-study project 1 and the construction manager, site engineer and site foreman in case-study project 3 that the causes of errors and violations in construction were rooted in the behavioural acts of people working on site. Also, the decision making by organisations to achieve a high productivity level often resulted in errors and violations. Thus, it was reported by a junior site 


\section{ALL VISITORS TO REPORT TO SIIE OFFICE, PLEASE ADHERE TO THE FOLLOWING

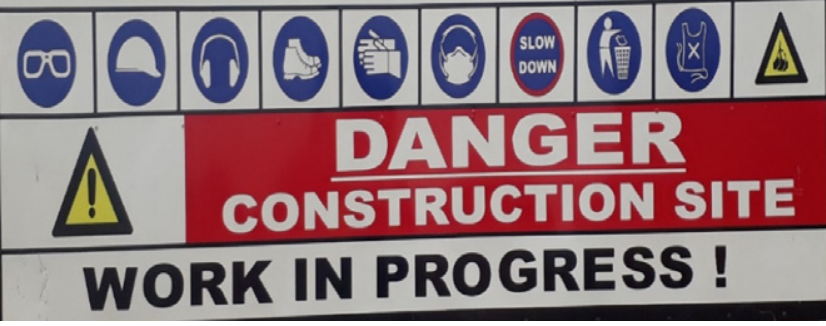

Figure 1. Safety warning signage

engineer in case-study project 2 that the desire to reach a high level of productivity often compels site management to create an unsafe working environment, which results in poor housekeeping. Figure 2 shows an example of poor housekeeping observed in case-study project 3 .

It was also reported by a senior foreman in case-study project 1 and a site engineer in case-study project 2 that poor housekeeping is a serious man-made cause, which leads to accidents

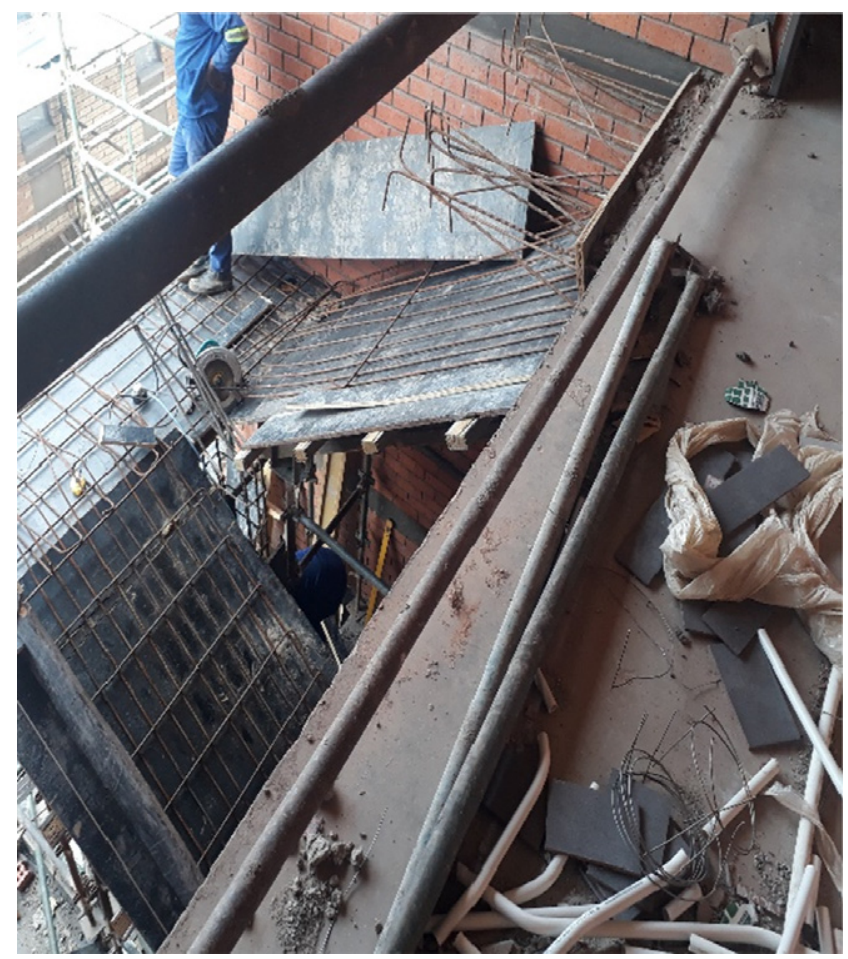

Figure 2. Poor housekeeping due to hazards that are not prevented or controlled. A student supervisor in case-study project 2 reported further that everyone on their construction site knew the importance of working in safe conditions but people tend to forget the safety policy of their organisation, especially bricklayers who tend to throw the broken bricks all over their work stations.

This is one of the factors causing poor housekeeping on our project sites and our management tend to ignore this behaviour due to the high level of performance produced by the bricklayer.

In response to how an SMS would be used to identify hazards and risks on construction sites, it was reported by most of the participants in the case-study projects that their safety managers were using a safe work procedure and a risk assessment tool to identify the risks that might cause hazards and how to prevent such risks or hazards from causing accidents. However, despite the use of a risk assessment plan and safe work procedure it was reported by several participants that, in case-study project 2, a worker was injured by a ready-mix concrete drum. Also, a safety manager and construction manager in case-study project 3 explained that one of their workers fell from a roof while cutting an overhang of a rafter. During the investigation, it was discovered that the worker did not install the safety harness while he was on top of the roof rafter.

Therefore, it can be suggested that, in case-study project 3, even though the safety management team identified fall as a hazard, and the worker was given a safety harness, they failed to monitor compliance with the specified measure to avoid the hazard which was for the worker to attach the safety harness to the rafter while cutting an overhang. It was reported by a construction manager in case-study project 2 that the most difficult activities on construction sites were to ensure that everyone complied with the safety regulations. He explained further that it was critical for the safety management team to promote regular safety training for workers to understand the adopted safety regulations.

It was reported also by a safety manager in case-study project 2 that they were responsible to organise safety training for all the workers on their project site. He explained further that one of the biggest challenges experienced in the construction industry was that most people tended to regard a toolbox talk as safety training. Hence, a senior site quantity surveyor in case-study project 2 stated that safety training must be conducted at the different stages of the project and that training for the general workers must not be combined with training for the management team. A safety observation inspection was also recommended as an alternative method to ensure compliance with safety measures on-site. It was reported further by 
Table 6. Results of statistical reliability test of elements of SMS

\begin{tabular}{|lcc|}
\hline $\begin{array}{l}\text { Cronbach's } \\
\text { alpha }\end{array}$ & $\begin{array}{c}\text { Cronbach's alpha based on } \\
\text { standardised items }\end{array}$ & $\begin{array}{c}\text { Number of } \\
\text { items }\end{array}$ \\
\hline 0.993 & 0.993 & 8 \\
\hline
\end{tabular}

some of the participants in the case-study projects that safety training, which is an element of SMS, was used to benchmark the safety practice on the construction sites and that their organisations must provide training facilities which could be used to improve how their safety managers carry out the safety training procedures on their project sites.

\subsection{The relation between inadequate SMS implementation and errors and violations}

Table 5 shows the extent to which a lack of the eight SMS elements contributes to errors and violations on project sites. The Likert scale of 0-5 was adopted to analyse the collected statistical data, using SPSS. The survey results provided evidence that failure to address the elements of SMS could lead to errors and violations on project sites. Notably, seven of the eight identified SMS elements were rated above the midpoint of 3.00, which suggests that these elements are significant. This statistical data validated the qualitative data collected from the case-study projects because it reinforced that SMS is used to identify hazards on project sites, and hazard identification was rated as the first SMS element that must be addressed on project sites.

Table 6 shows the reliability test of the eight elements of SMS. Based on the reliability test results, using SPSS, it was notable that the Cronbach's alpha was recorded at 0.993 and the Cronbach's alpha on Standardised Items was recorded at 0.993. Based on the fact that, in social science research, a reliability coefficient of 0.70 or higher is considered to be acceptable, it could be concluded that the statistical data presented in Table 5 was reliable.

\section{Discussion}

Evidence across the cases in this study indicated that effective SMS helps to control hazards and risks on project sites. Yiu et al. (2018) pointed out that SMS signifies a designed system that enables management to prevent OHS incidents and accidents. SMSs are used to control operational risks to prevent accidents (Accou and Reniers, 2019). These functions of SMSs is corroborated by the interviewees in the case projects who reported that their employers hire safety managers to design and manage an effective SMS. The designed SMS helps to identify and eliminate hazards and risks that had the potential to cause accidents. The reported decision of employers (construction directors/owners) to hire safety managers to design and manage an SMS is supported by Perlman et al. (2014). The authors explained that the implementation of an SMS must be managed by a competent site manager who would develop a model to identify hazards and risks to reduce accidents.

Table 5 shows that hazard identification was rated as the most important SMS element in preventing errors and violations on project sites. However, case project 3 shows that hazard identification is not addressed by site management on project sites. For instance, Figure 2 shows the observed poor housekeeping that exposes hazards in the form of wasted materials. Inadequate hazard identification could result in errors and violations on construction sites. The effect of inadequate hazard identification is evident in the work of Reese and Eidson (2006) who contend hazards experienced in construction are caused by equipment used on worksites, a view that was corroborated by the interviewees. For example, an interviewee in case study project 2 reported an accident in which a general worker lost his finger while working with a ready-mix concrete drum. Based on the responses presented in Table 5, it could be argued that had the site management in case-study project 2 implemented a risk assessment plan, conducted OHS training on-site and effective safety inspection, this accident could have been prevented.

The OHS functions of site management start with the prevention of incidents and accidents, which are rooted in errors and violations (Perlman et al., 2014). In essence, there appears to be a good practice among the case projects where employers hire safety managers to design an SMS to prevent accidents. The SMSs are designed according to the Construction Regulations 2014. However, despite designing SMS according to the Construction Regulations 2014, site management from the case study projects continued to experience accidents. The occurrence of accidents despite the deployment of SMSs is a concern that should be addressed.

\section{Conclusions}

The purpose of implementing an SMS in construction is to mitigate the risk of injuries, reduce workplace hazards and minimise property damage. In this study, it was found that SMSs are designed by the safety management team to promote a safe working environment by identifying and eliminating hazards that might cause accidents on the worksite. However, deploying SMSs based on the Construction Regulations of 2014 was not enough to prevent accidents in South African construction. In particular, contractors in the case projects in South Africa were still struggling to mitigate risks and reduce hazards that have resulted in accidents. For instance, in case-study projects 2 and 3, both contractors experienced accidents, which resulted in injuries. The causes of such injuries could be connected to errors and violations 
involving injured workers. Such injuries could have been prevented if an appropriate risk assessment plan, hazard identification, OHS training, safe work procedures and safety inspections had been conducted by site management. Therefore, it can be concluded that the recommendations of the professionals who participated in the survey, regarding the rating of the SMS elements, were correct. The causes of the injuries reported in this study were linked to inadequate SMS implementation, which was deployed on project sites. The concern can be addressed by workers and management working together to improve the SMS in the worksites.

\section{REFERENCES}

Accou B and Reniers G (2019) Developing a method to improve safety management systems based on accident investigations: the safety fractal analysis. Safety Science 115: 285-293.

Alli B (2008) Fundamental Principles of Occupational Health and Safety. 2nd edn. International Labour Organization (ILO), Geneva, Switzerland.

Álvarez-Santos J, Miguel-Dávila JA, Herrera L and Nieo M (2018) Safety management system in TQM environments. Safety Science 101: 135-143.

Bryman A (2012) Social Research Methods. 4th edn. Oxford University Press, Oxford, UK.

DoL (Department of Labour) (2017) Labour on Injuries and Fatalities in SA Construction Sector. Department of Labour, Pretoria, South Africa. See https://www.gov.za/speeches/sa-construction-sector-9mar-2017-0000 (accessed 14/02/2020).

Fan D, Lo CK, Ching V and Kan C (2014) Occupational health and safety issues in operations management: a systematic and citation network analysis review. International Journal of Production and Economics 158: 334-344.

Flick U (2014) An Introduction to Qualitative Research. 5th edn. Sage Publications, London, UK.

Hamid A, Majid MZ and Singh B (2008) Causes of accidents at construction sites. Malaysian Journal of Civil Engineering 20(2) 242-259.

Hancock DR and Algozzine B (2011) Doing Case Study Research: A Practical Guide for Beginning Researchers. Teachers College Press, New York, NY, USA.

HSE (Health and Safety Executive) (2019a) Kinds of Accident Statistics in Great Britain, 2019. The Health and Safety Executive, London, UK. See https://www.hse.gov.uk/statistics/causing/kindsof-accident.pdf.

HSE (2019b) Human Factors: Managing Human Failures. HSE, London, UK. See https://www.hse.gov.uk/humanfactors/ topics/humanfail.htm (accessed 13/09/2020).

Ismail F, Hashim AH, Ismail WZW, Kamarudin $\mathrm{H}$ and Baharom ZA (2012) Behaviour based approach for quality and safety environment improvement: Malaysian experience in the oil and gas industry. Procedia - Social and Behavioral Sciences 35: $586-594$

McKinnon R (2019) The Design, Implementation, and Audit of Occupational Health and Safety Management Systems. CRC Press, New York, NY, USA.

Park CS and Kim HJ (2013) A framework for construction safety management and visualization system. Automation in Construction 33: $95-103$.
Perlman A, Sacks R and Barak R (2014) Hazard recognition and risk perception in construction. Safety Science 64: 22-31.

Plano Clark V and Ivankova NV (2016) Mixed-Method Research: A Guide to the Field. Sage Publication, Los Angeles, CA, USA.

Reason J (2016) Organizational Accidents Revisited. Ashgate, Surrey, NY, USA.

Reese CD and Eidson JV (2006) Handbook of OSHA Construction Safety and Health. 2nd edn. Taylor \& Francis Group, New York, NY, USA

Shafique M and Rafiq M (2019) An overview of construction occupational accidents in Hong Kong: a recent trend and future perspectives. Applied Science 9(2069): 1-16.

Wachter JK and Yorio PL (2014) A system of safety management practices and worker engagement reducing and preventing accidents: an empirical and theoretical investigation. Accident Analysis and Prevention 68: 117-130.

Yiu NSN, Sze NN and Chan DWM (2018) Implementation of safety management systems in Hong Kong construction industry - a safety practitioner's perspective. Journal of Safety Research 64: $1-9$.

Yiu NSN, Chan DWM, Shan M and Sze NN (2019) Implementation of the safety management system in managing construction projects: benefits and obstacles. Safety Science 117: 23-32.

Zou PX, Lun P, Cipolla D and Mohamed S (2017) Cloud-based safety information and communication system in infrastructure construction. Safety Science 98: 50-69.

\section{How can you contribute?}

To discuss this paper, please email up to 500 words to the editor at journals@ice.org.uk. Your contribution will be forwarded to the author(s) for a reply and, if considered appropriate by the editorial board, it will be published as discussion in a future issue of the journal.

Proceedings journals rely entirely on contributions from the civil engineering profession (and allied disciplines).

Information about how to submit your paper online is available at www.icevirtuallibrary.com/page/authors, where you will also find detailed author guidelines. 